\title{
Effects of an Online Acceptance and Commitment Therapy Intervention on Children's Quality of Life
}

\author{
Essi Sairanen (1) ${ }^{1} \cdot$ Raimo Lappalainen ${ }^{2} \cdot$ Päivi Lappalainen $^{2} \cdot$ Arto Hiltunen $^{1}$
}

Accepted: 8 January 2022 / Published online: 26 January 2022

(c) The Author(s) 2022

\begin{abstract}
The present study examined if an Acceptance and Commitment Therapy (ACT)-based online intervention for parents had indirect effects on their children's quality of life mediated by changes in parental well-being, psychological flexibility and mindfulness skills. Participants were 74 adults, who either received an ACT-based guided online intervention or were allocated to the wait list control group, and their children $(n=66)$ who had type 1 diabetes or functional disabilities. Structural equation modeling (SEM) and a bias-corrected bootstrap approach were applied to examine the indirect effects of the treatment on children's quality of life through changes in parents' well-being and psychological processes involving psychological flexibility, cognitive defusion, and mindfulness skills. Children's quality of life was assessed both by selfreports and parents' evaluations. Significant indirect effects on children's quality of life were found through improvements in parental well-being and mindfulness skills. The intervention had significant indirect effects on parents' evaluations of their children's quality of life concerning family and other social relationships, as well as on physical well-being. In regard to children's self-reported quality of life, the intervention had significant indirect effects on self-esteem, family relations, emotional well-being, and functioning at school/kindergarten. The results indicate that it is beneficial for children's quality of life to improve parents' ability to describe their experiences, being non-reactive to one's inner experiences and acting with awareness as well as cognitive defusion.
\end{abstract}

Keywords Children's quality of life $\cdot$ Parental well-being $\cdot$ Acceptance and commitment therapy $\cdot$ Online intervention

\section{Highlights}

- Parents of children with chronic conditions can benefit from an ACT web intervention leading also to increased quality of life in children.

- Children quality of life improved though improvements in parental wellbeing and mindfulness skills.

- Improving parents' ability to describe their experiences, being non-reactive to one's inner experiences and acting with awareness it is beneficial for children's quality of life.

The chronic illness or disability of a child is a risk to the psychological well-being of both the child and parents (Bennett, 1994). A child's chronic condition or functional disability can increase the parents' worries and stress in

Essi Sairanen

essi.sairanen@kau.se

1 Department of Social and Psychological Studies, Karlstad University, SE-651 88 Karlstad, Sweden

2 Department of Psychology, University of Jyväskylä, PO Box 35, FI-40014 Jyväskylä, Finland everyday life, which can result in some form of chronic stress reaction and burnout syndrome (Appels \& Schouten, 1991; Melamed et al., 1992; Toker et al., 2005) Parental distress and burnout, in turn, can affect parental practices and family functioning (Kim-Cohen et al., 2005; Witt \& DeLeire, 2009) and hence have an impact on children's quality of life. Accordingly, it is important to develop technologies for supporting parents' well-being and parenting abilities in families with a child having a chronic condition. Online treatments provide an opportunity to improve the accessibility of evidence-based treatments for parents who may have difficulty finding time for themselves. 
One promising approach for this population is Acceptance and Commitment Therapy (ACT), that is, one of the third-wave cognitive behavioral therapies that incorporates methods of acceptance, mindfulness, defusion, and values (Hayes et al., 2006), thus teaching psychological skills that can be integrated in parents' daily activities, including interaction with their children. The aim of these methods is to increase psychological flexibility, which is defined as the ability to persist or change one's own behavior in the service of one's chosen values while being aware of the situational context and one's own present moment experience (Kashdan \& Rottenberg, 2010). More precisely, psychological flexibility is targeted by improving the ability to be in contact with personally important values and one's own inner experiences, moment-to-moment, in a nonjudgmental way (i.e., acceptance), and to see one's own thoughts as an ongoing mental activity without getting caught up in them (i.e., cognitive defusion), and also to commit to personally meaningful actions.

Previous research suggests that parents' psychological flexibility is one important factor explaining parenting practices and can thereby impact children's well-being and quality of life. Increased parental psychological flexibility has been found to be related to a greater use of positive parenting strategies (Burke et al., 2014), whereas parents' self-reported psychological inflexibility has been shown to correlate positively with punitive and inconsistent parenting styles (Cheron et al., 2009; Shea \& Coyne, 2011) and negatively with maternal responsiveness (Evans et al., 2012). In addition, a connection between parents' psychological flexibility and their child's psychological outcomes has been demonstrated (Cheron et al., 2009; Williams et al., 2012).

Similarly, studies have shown that parents with higher levels of mindfulness, characterized by intentionally bringing mindful awareness and compassion to everyday parent-child interactions and adopting an attitude of nonjudgmental acceptance of oneself as a parent while acting according to one's parenting values (Bögels et al., 2014; de Bruin et al., 2014), adopt more positive parenting styles and practices as well as demonstrating more positive interactions and communication with their children (Gouveia et al., 2016; Lippold et al., 2015; Parent et al., 2016). Moreover, parents' mindfulness skills have been associated with lower levels of psychological symptoms in children, such as lower levels of depression, anxiety, and internalizing and externalizing symptoms, as well as with increased well-being (Bögels et al., 2014; Moreira et al., 2018; Parent et al., 2016). Accordingly, enhancing mindfulness skills and psychological flexibility in the context of parenting is recommended, given the influence parenting behavior has on their children's well-being and quality of life.

ACT has been applied widely to different problems and populations (Hayes et al., 2006; Ruiz, 2010), and the effectiveness of ACT has also been supported in an online format (e.g., Buhrman et al., 2013; Lappalainen et al., 2014). An increasing number of studies applying Acceptance and Commitment Therapy (ACT) interventions to parents have supported its suitability for this type of population, including parents of children with autism (Blackledge \& Hayes, 2006; Hahs et al., 2019), cerebral palsy (Whittingham et al., 2016), chronic pain (Kanstrup et al., 2016; Kemani et al., 2018; Wallace et al., 2016), asthma (Chong et al., 2019), and cancer or life-saving cardiac surgery (Burke et al., 2014). A recent systematic review (Byrne et al., 2021) covering 27 ACT interventions for parents concluded that the majority of studies reported improvements in either parent-reported symptoms regarding child physical or psychological functioning as well as in parent-reported measures of stress, depression, and anxiety. Improvements were noted also in a number of ACT mechanisms of change outcomes, including mindfulness, acceptance, and cognitive defusion. These gains were evident for parents of children with neurodevelopmental disorders, chronic pain, and significant physical health difficulties (Byrne et al., 2021). In line with these findings, in our previous randomized controlled trial (RCT), we investigated a 10 -week online ACT intervention with parents of children having chronic illness or functional disabilities [Blinded]. It was demonstrated that the online ACT was associated with a decrease in parents' burnout symptoms and psychological distress and improvements in mindfulness skills from the beginning of the intervention to the four-month follow-up, relative to the waitlist control group.

In the present study, secondary outcomes of the RCT regarding children's quality of life are explored. We are interested in whether the decrease in parents' burnout symptoms and the improvements in psychological flexibility processes (i.e., acceptance and value-based actions, mindfulness, defusion) mediated the intervention effect on children's quality of life. Based on the previous findings and the ACT model, we assumed that an ACT intervention for parents can have a positive impact on children's quality of life by providing the parents with skills for taking better care of themselves and improving their own well-being. In addition, we expected that an ACT intervention could increase parents' awareness of their parenting-related values (i.e., "How do I want to be as a parent?") and help them to handle their own emotional reactions (e.g., fear, frustration) and stressors in a more efficient way, so that they would be better equipped to stay present for their children and respond to their needs.

The research questions of our study were: (1) Does an online ACT intervention for parents affect their children's quality of life; that is, does the quality of life for children whose parents participated in an online ACT intervention 
improve from pre to post and follow-up measurements compared to the children whose parents participated in a waitlist control (WLC) group? (2) Do decreases in parents' burnout symptoms and improvements in their psychological flexibility processes (i.e., acceptance and value-based actions, defusion, mindfulness) from pre to follow-up measurements mediate the intervention effect on their children's quality of life according to both parents' estimations of their children's quality of life and the children's self-reports?

\section{Methods}

\section{Participants}

Parents $(n=74)$ suffering from burnout symptoms (i.e., score exceeding 2.75 points on the Shirom-Melamed Burnout Questionnaire) (Shirom \& Melamed, 2006) and their children ( $n=66$, from birth to age 18 ) with type 1 diabetes or functional disabilities participated in the study.

The parents were on average 42.7 years old $(\mathrm{SD}=6.9)$; $19 \%$ were men and $81 \%$ women. $80 \%$ of the parents were married or living with a partner, and $73 \%$ had a postsecondary or university-level education. Of the participating parents' children, $42 \%$ were girls and $58 \%$ boys. The children were on average $10.3(\mathrm{SD}=4.5)$ years old at the time of the study, and on average $4.8(\mathrm{SD}=3.6)$ years old at the time of being diagnosed. Diagnoses and groupspecific sample characteristics of the children are presented in Table 1.

Table 1 Sample characteristics of the children whose parents either participated in the online act intervention or were in the waitlist control group

\begin{tabular}{lcc}
\hline & $\begin{array}{l}\text { ACT group } \\
(n=34)\end{array}$ & $\begin{array}{l}\text { Control group } \\
(n=32)\end{array}$ \\
\hline $\begin{array}{l}\text { Child gender (female/male) } \\
\text { Child age, years [mean (SD)] }\end{array}$ & $16 / 18$ & $12 / 20$ \\
$\begin{array}{l}\text { Child age when diagnosed } \\
\text { Diagnosis of the child: }[n(\%)]\end{array}$ & $5.0(3.9)$ & $4.6(3.2)$ \\
$\quad \begin{array}{l}\text { Diabetes } \\
\text { Chromosomal abnormality or } \\
\text { genetic disorder }\end{array}$ & $3(9)$ & $15(40)$ \\
$\begin{array}{l}\text { Hypoxic-ischemic } \\
\text { brain damage }\end{array}$ & $2(6)$ & $4(13)$ \\
$\begin{array}{l}\text { Autism spectrum disorders } \\
\text { Motor disorders }\end{array}$ & $6(18)$ & $4(13)$ \\
$\begin{array}{l}\text { Developmental disability or } \\
\text { other/unknown etiology }\end{array}$ & $2(6)$ & $1(3)$ \\
\hline
\end{tabular}

\section{Online Acceptance and Commitment Therapy intervention}

Detailed information about the online ACT intervention can be found in the article by [reference blinded], and the intervention is briefly presented here.

The 10-week online program was called ACTParents. Based on the psychological flexibility processes, the intervention aimed to teach parents skills and strategies to handle stress and other psychological experiences in everyday life. Participants had no face-to-face contact with their coach, but a semi-structured phone interview concerning lifestyle, social relationships and well-being was conducted before starting the online intervention. ACTParents consisted of five modules that the participants were instructed to process during the course of 1-2 weeks. Modules had different themes, such as life values, being present, acceptance, defusion, and self-compassion (see Table 2). Each module consisted of text and video materials, questionnaires and exercises; so the information could be read or listened to. Participants could also write a diary for themselves and discuss issues with each other in the discussion forum. Participants were asked to complete a home assignment related to each theme of the module (after every 1-2 weeks) and to submit their reflection based on their experiences with the assignment to their coach via the program platform. The participants received written semistructured feedback on their assignment and reflection from their coach. The semi-structured feedback was prepared by ACT professionals in order to make sure that it is in line with ACT principles, and it included instructions for the coaches on how to personalize the feedback according to the participants' reflections.

The coaches were undergraduate psychology students, who received a 4-hour training in ACT online coaching. The training was provided by an experienced clinician, a licensed psychologist, and a psychotherapist, representing nearly 15 years of experience in ACT clinical practice and supervision. In addition, the coaches received $2 \mathrm{~h}$ of supervision once during the intervention period and further help for writing feedback when needed from the members of the research group who had extensive experience with ACT-based interventions.

\section{Measures}

\section{Children's quality of life}

Children's quality of life was measured by using the $\mathrm{KINDL}^{\mathrm{R}}$, a generic instrument for assessing the healthrelated quality of life of children and adolescents aged 3 years and older (Ravens-Sieberer \& Bullinger, 1998). Three different versions of the instrument, suitable for different 
Table 2 Content of the ACTParents online program

Modules

Introduction

Module 1: What is important for you?

(Values)

Assignment, week 2

Module 2: Meaningful actions! (Valuebased actions)

Assignment, weeks 3-4

Module 3: Present moment (Present moment experience)

Assignment, weeks 5-6

Module 4: Distance from thoughts and feelings (Defusion)
Content of the ACTParents program

Welcome to the program

Text:

To be a parent

Where are you going?

Video: Important for You

Experiential exercises (read or listen):

The most important things in life

Find what is meaningful in life

90th birthday party

Reflect on your life values and formulate them. Choose one or more areas of life and life values that feel right for you right now. Act! Think about what action you can perform today.

Text:

Meaningful actions

Obstacles on the road

Sleep, fatigue

Experiential exercises:

Do it now!

Accept your fatigue

Select your three most important life values and goals, and make a plan to start your journey toward these values. Create a calendar and schedule some activities for tomorrow, next week, next month, etc. Write down your plan as in the example:

- My life value (what matters to me) is:...

- My intermediate goals toward this value are as follows:

$1 \ldots 2 \ldots 3$...

-When will you take the first step? Today, tomorrow, next week?

Text:

Present moment

Present moment in everyday life

Video: Mindfully present

Experiential exercises:

Let go

Follow your breath

Mindful in everyday tasks

Washing dishes mindfully

Mindful eating

Mindful listening

Body scanner

SOAL: Stop, Observe, Accept, Let go

1. Apply the SOAL method in your everyday life: Stop, observe, accept, and let go.

2. Use a "present moment thermometer" every night and note how present you have been during the day. Note the activities that have helped you be more present (e.g., hobby, mindful shower, mindful eating, music, dance, yoga, exercises). Try to increase the frequency of activities that make you focus more on the moment and feel good.

3. How can you influence your well-being? What actions promoting the good life for you are you willing to choose today or tomorrow?

Text: Thoughts are just thoughtsVideo: The power of thoughts and feelings

Experiential exercises:

The little man

Leaves in the stream

Observer 
Table 2 (continued)

\begin{tabular}{|c|c|}
\hline Modules & Content of the ACTParents program \\
\hline Assignment, weeks 7-8 & $\begin{array}{l}\text { 1. Put a label on your thoughts, feelings, and bodily sensations } \\
\text { as they appear. Speak out loud to yourself, for example: Now I } \\
\text { get the feeling that I'm sad ..., } \\
\text { Now I have the idea to ... (describe the idea), } \\
\text { Now I get the feeling to/that ... (describe the feeling), } \\
\text { Now the memory came up of ... (describe the memory), } \\
\text { Now it feels like my body is ... (describe the sensation). }\end{array}$ \\
\hline $\begin{array}{l}\text { Module 5: Openness (Acceptance and } \\
\text { self-compassion) }\end{array}$ & $\begin{array}{l}\text { Text: Acceptance, Self-compassion } \\
\text { Video: Acceptance } \\
\text { Experiential exercises: } \\
\text { Tug-of-war } \\
\text { Don't think about the cinnamon bun } \\
\text { Broken machine } \\
\text { Increase your oxytocin levels } \\
\text { Self-compassion exercise } \\
\text { A good friend }\end{array}$ \\
\hline Assignment, weeks 9-10 & $\begin{array}{l}\text { 1. Is there anything in your life that you need to learn to accept? } \\
\text { Select any of the acceptance exercises above, or apply the } \\
\text { general model of acceptance to what you have difficulty in } \\
\text { accepting. Practice acceptance several times a week: } \\
\text { (a) Note and describe the present moment. } \\
\text { (b) Accept what you note. } \\
\text { (c) Accept your painful and unpleasant thoughts and feelings. } \\
\text { (d) Do not avoid. } \\
\text { 2. Be compassionate with yourself and others. Reflect and tell } \\
\text { how it feels and affects you and people close to you. } \\
\text { Deliberately seek pleasures in your life every day. }\end{array}$ \\
\hline Closing words & $\begin{array}{l}\text { Summary of the program ( } 2 \text { pages) } \\
\text { Text: } \\
\text { The journey continues } \\
\text { Over the highest mountains }\end{array}$ \\
\hline
\end{tabular}

age groups and developmental stages, were used. Each version of the questionnaire was completed both by the children or adolescents and their parents.

The KINDL ${ }^{\mathrm{R}}$ questionnaire consists of 24 items associated with six dimensions: physical well-being, emotional well-being, self-esteem, family, friends, and everyday functioning (school or nursery school/kindergarten). The subscales of these six dimensions can be combined to produce a total score. The items are rated on a 5 -point Likert-type scale ranging from $1=$ never to $5=$ all the time. The exception is the self-report version for children under age seven, which only consists of twelve items (2 for each dimension). This means that subscale scores cannot be calculated for the individual dimensions, only a total score. These items are rated on a 3-point Likert-type scale: 1 =never, 2 =sometimes, 3 =very often. Higher scores indicate better quality of life. The questions in the KINDL are based on statements like, "My child felt alone" and "My child felt pleased with himself/ herself." The structure, reliability and validity of the KINDL have been demonstrated (Ravens-Sieberer \& Bullinger, 1998; Ravens-Sieberer et al., 2000).

\section{Parents' well-being}

The main intervention outcome measure assessing burnout symptoms, the Shirom-Melamed Burnout Questionnaire (SMBQ), was chosen for the analysis. Secondary measures of parents' psychological symptoms (i.e., Depression Anxiety Stress Scales, DASS-21) (Henry \& Crawford, 2005) were excluded from the current study in order to limit the number of analyses.

Burnout symptoms The Shirom-Melamed Burnout Questionnaire (SMBQ) (Lundgren-Nilsson et al., 2012; Melamed et al., 1999; Shirom \& Melamed, 2006) consists of 22 items that are rated on a 7-point Likert-type scale ranging from $1=$ never or almost never to $7=$ always or almost always, with higher scores indicating stronger symptoms of burnout (i.e., exhaustion, fatigue, tension, cognitive weariness). The questions in the SMBQ are based on statements like,"I feel tired," "I feel I am not thinking clearly," and "I feel tense." The cutoff scores are 2.75-3.74 for low burnout, 3.75-4.46 for high burnout, and $\geq 4.47$ for a pathological level of burnout. 
The SMBQ's reliability and validity have been demonstrated elsewhere (Lundgren-Nilsson et al., 2012; Shirom \& Melamed, 2006). In our data, Cronbach's alpha was 0.91 at the baseline, 0.93 at the post-intervention, and 0.98 at the follow-up measurement times.

\section{Parents' psychological processes}

Three psychological process variables measuring different aspects of psychological flexibility used in the RCT were chosen for this secondary analysis (1. Psychological flexibility or Acceptance and value-based action, 2. Mindfulness, and 3. Cognitive defusion).

Psychological flexibility Psychological flexibility was assessed with the Acceptance and Action Questionnaire (AAQ-II) (Bond et al., 2011). All 7 items of the scale are rated on a 7-point Likert-type scale ranging from $1=$ never true to $7=$ always true, with higher scores indicating lower levels of psychological flexibility. The AAQ-II assesses the ability to take value-based actions in the presence of difficult inner experiences. The questions in the AAQ-II are based on statements like, "My painful experiences and memories make it difficult for me to live a life that I would value." Regarding the present data, Cronbach's alpha was 0.90 at the baseline, 0.95 at the post-intervention, and 0.94 at the follow-up measurement times. The structure, reliability and validity of the AAQ-II have been reported in a previous study (Bond et al., 2011).

Mindfulness Mindfulness was assessed with the Five Facets Mindfulness Questionnaire (FFMQ) (Baer et al., 2008). All 39 items of the scale are rated on a 5-point Likert-type scale ranging from $1=$ never or very rarely true to $5=$ very often or always true. Higher scores indicate higher levels of mindfulness skills. The scale has five subscales measuring different aspects of mindfulness: (a) Observing (e.g., "I pay attention to physical experiences, such as the wind in my hair or the sun on my face"); (b) Describing (e.g., "I'm good at finding the words to describe my feelings"); (c) Acting with awareness (e.g., "I find it difficult to stay focused on what is happening in the present moment"); (d) Non-judgment of inner experiences (e.g., "I tell myself that I shouldn't be feeling the way I'm feeling"); (e) Non-reactivity to inner experiences (e.g., "I observe my feelings without getting carried away by them"). In our data, Cronbach's alpha was at the baseline/ post/ follow-up measurement times, respectively: the total FFMQ score 0.86/0.94/0.94, Observing 0.78/0.89/0.80, Describing 0.92/ $0.92 / 0.94$, Acting with awareness 0.91/0.94/0.94, Nonjudgment $0.92 / 0.93 / 0.93$, and Non-reactivity $0.82 / 0.88 /$ 0.89 . The reliability and validity of the FFMQ have been demonstrated before (Baer et al., 2008).
Cognitive defusion Cognitive defusion was assessed with the Cognitive Fusion Questionnaire (CFQ) (Gillanders et al., 2014). All 7 items of the scale are rated on a 7-point Likert-type scale ranging from $1=$ never true to $7=$ always true, with higher scores indicating higher levels of cognitive fusion and accordingly lower levels of defusion. The CFQ assesses how distressing thoughts are experienced by a person, how much one struggles with one's own thoughts, and whether that stops individuals from taking actions. The questions of the CFQ-13 are based on statements like, "I struggle with my thoughts". In our data, Cronbach's alpha for the CFQ data was 0.94 at the baseline, 0.95 at the postintervention and 0.95 at the follow-up measurement times, which is in line with a previous study demonstrating the reliability and validity of the CFQ (Gillanders et al., 2014).

A Swedish version of the measures was used. The measures have been translated and back-translated for previous studies (Alfonsson et al., 2017; Lilja et al., 2011; Lundgren \& Parling, 2017; Lundgren-Nilsson et al., 2012), except for the CFQ, which was translated for this study by a group of researchers with extensive experience with ACTbased interventions.

\section{Procedure}

The present study received ethical approval from the Regional Ethical Review Board of Uppsala University in Uppsala, Sweden. All participants gave their written informed consent for their participation in the study.

The data were collected in two phases, the first group starting in the spring of 2017 and the second in the fall of 2017. The parents were recruited through the pediatric clinic and the pediatric habilitation center of the County Council of [Blinded], Sweden, by sending an invitation letter to parents of children with type 1 diabetes or functional disabilities. The invitation letter provided information about the research, including a brief description of the online ACT intervention, measurements and purpose of the research.

Participants enrolled in the study via email or by phone. The exclusion criteria were assessed through an online survey, including an electronic questionnaire for reported burnout symptoms (SMBQ). In order to be included in the study, the parents needed to be suffering from burnout symptoms (i.e., score exceeding 2.75 points on the Shirom-Melamed Burnout Questionnaire) (Shirom \& Melamed, 2006). Persons undergoing any other psychological treatment, as well as those who could not fill out the questionnaires in Swedish, were excluded from the study.

After completing the screening questionnaires (SMBQ) along with the informed consent, participants who met the inclusion criteria were randomly assigned, by a researcher outside of the research group, either to the online ACT 
intervention or the waitlist control (WLC) group. Block randomization was performed to ensure (close to) an equal number of subjects in each group. Randomization was applied using SPSS software (Arifin, 2012). In addition, participants in the ACT group were randomly assigned to one of the 17 coaches. Couples were randomized together; the ACT group included three couples (37 participants) while the control group had five couples (37 participants).

Before starting the intervention (or the waitlist period), the parents completed an online survey regarding demographic variables, their own well-being and psychological processes (including AAQ, FFMQ, CFQ), and their children's quality of life (KINDL). All outcome and process measures (including SMBQ, AAQ, FFMQ, CFQ, and KINDL) were completed again via an online survey at the end of the 10-week intervention or waitlist period, plus 4 months after the intervention (follow-up). Regarding the children's quality of life, the parents of children under 7 years of age were instructed to ask their child to tell them their answer to each stipulated question, whereas older children were asked to fill out the questionnaire themselves.

\section{Summary of Previously Reported RCT Results}

The effects of the online ACT intervention were investigated using hierarchical linear modeling (HLM) (Wald test), comparing the change in the treatment group to the change in the waitlist control group from pre to post and follow-up [Reference blinded]. Significant positive intervention effects (group $\times$ time interaction) were found for burnout symptoms (SMBQ), psychological distress, and depression. In addition, the positive intervention effects were significant for the total mindfulness score (FFMQ) and its subscales Observing, Describing, Acting with awareness, and Nonreactivity to inner experiences. Pre, post and follow-up scores of the variables that were included in the mediation analysis of the present study, as well as the effects of the intervention on parents' well-being and psychological processes, are presented in the Table 3.

\section{Statistical Analysis}

The statistical analyses were conducted using Mplus (Version 8). The parameters were estimated using the full information maximum likelihood method (MLR/MLF estimation in Mplus).

\section{Intervention effects on children's quality of life}

Hierarchical linear modeling (HLM, Wald test) was used to analyze the group $\mathrm{x}$ time interaction; that is, whether the groups changed differently between the measured time points (pre, post, follow-up). Post hoc tests were conducted to determine whether the difference between groups occurred during or after the intensive intervention period. Hierarchical linear modeling accounts for values missing at random (MAR) and includes all of the available data.

Effect sizes (ES) are reported as Cohen's $d$, which was calculated from the baseline to the follow-up within (and corrected between) groups to estimate effect sizes using the estimated values. A within-group ES of 0.5 is considered small, 0.8 medium, and 1.1 large; and a corrected between-group ES of 0.2 is considered small, 0.5 medium, and 0.8 large.

\section{Mediation analysis}

To assess the indirect effect of the treatment on children's quality of life through changes in their parents' burnout symptoms and process variables, the model depicted in Fig. 1 was proposed. Mediation analyses were conducted utilizing both the parents' estimations of their children's quality of life and the children's self-reports. In order to capture the maximum individual changes in variables, the time period from the pre to the follow-up measurement was chosen for mediation analysis. Concerning the couples, the data from both parents were included in the analysis, separately.

Structural equation modeling (SEM) was used to investigate whether changes in the parents' burnout symptoms and psychological processes mediated changes in their children's quality of life. The product of the $a b$ path was computed to assess the indirect effect of the intervention $(X)$ on the outcome $(Y)$ through the mediator $(M)$ directly. The only criterion required to demonstrate mediation is a significant indirect effect $(a \times b)$. Note that a statistically significant total effect of $\mathrm{X}$ on $\mathrm{Y}$ is not necessary for mediation to occur, and that mediation analysis does not require evidence of a total effect prior to investigating the indirect $(\mathrm{a} \times$ b) effect (Zhao et al., 2010).

Following the recommendations of Preacher and Hayes, bias-corrected $95 \%$ confidence intervals (CI) were calculated to assess the significance of the direct and indirect effects by using nonparametric bootstrapping procedures (Preacher \& Hayes, 2008). Confidence intervals are based on 1000 bootstrap resamples. If the $95 \%$ confidence interval (CI) for the estimate of indirect effects does not include zero then it indicates a statistically significant effect at the level of 0.05 . The standardized indirect effect provides a scalefree measure that allows a direct comparison of effects across differently scaled outcomes and can be used for synthesis across studies (Preacher et al., 2010).

The fit of each model was evaluated using the following goodness-of-fit measures, provided by the Mplus program (Muthén, 1998): RMSEA (Root Mean Square Error of Approximation, with values of 0.06 or less indicating a good fit); SRMR (Standardized Root Mean Square Residuals, with 


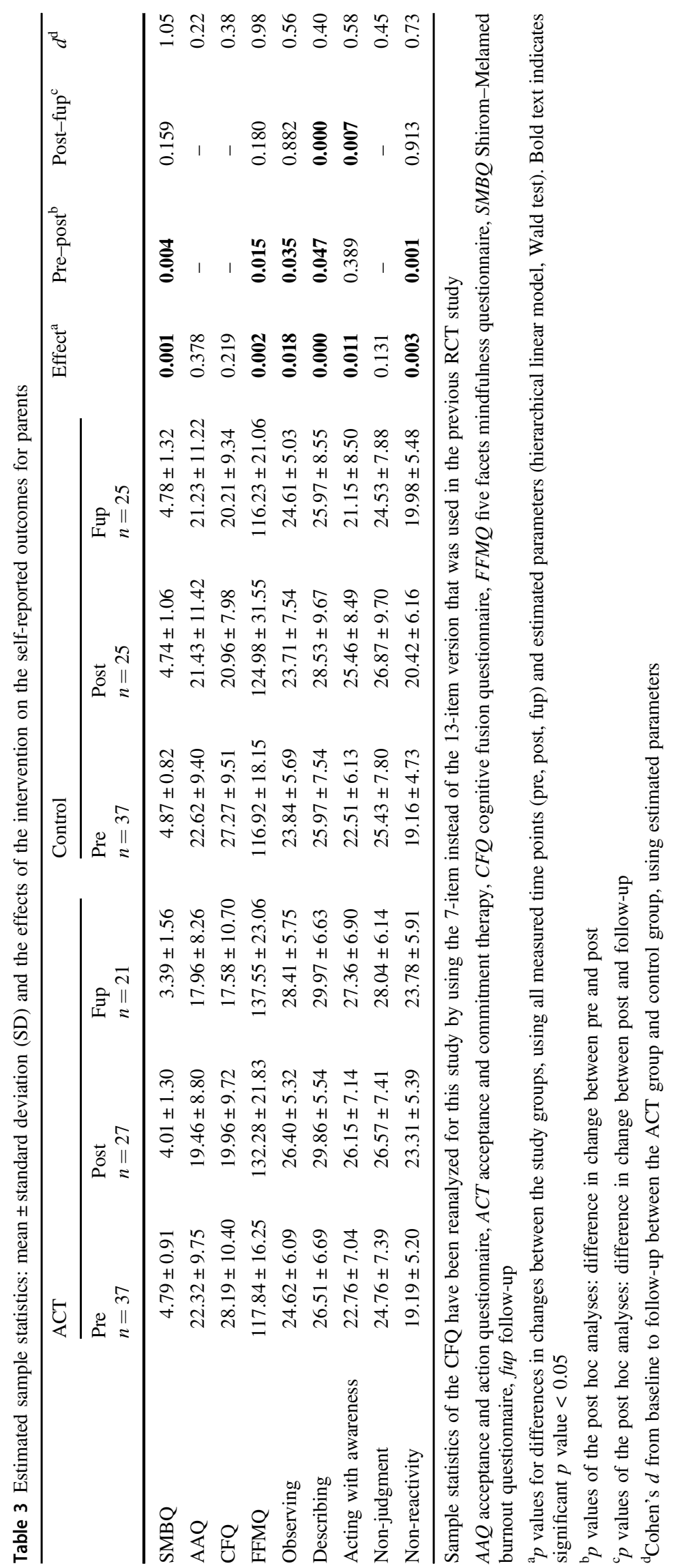




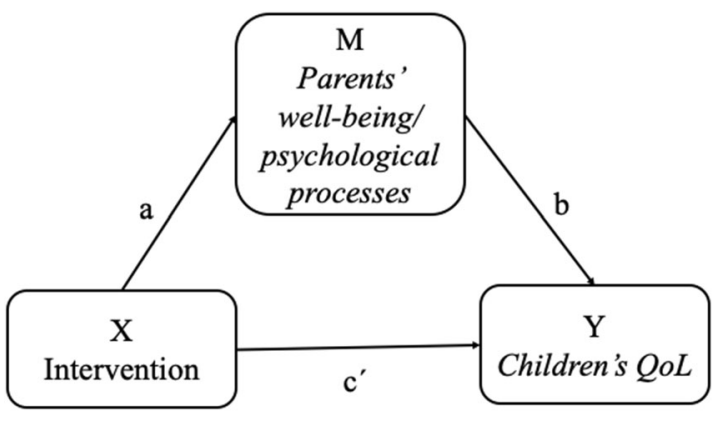

Fig. 1 Mediation model: change in parents' well-being and psychological flexibility processes mediates intervention effects on children's quality of life

values less than 0.08 indicating a good fit); CFI (Bentler's Comparative Fit Index, with values of 0.95 or higher indicating a good fit); and TLI (Tucker-Lewis Index, with values higher than 0.95 indicating a good fit) (Hu \& Bentler, 1999).

Using Monte Carlo simulation (Muthén \& Muthén, 2002; Schoemann et al., 2017; Thoemmes et al., 2010), post hoc power analyses were calculated for the mediation analysis with the change in parents' burnout symptoms (SMBQ) as a mediator and the change in children's quality of life $\left(\mathrm{KINDL}^{\mathrm{R}}\right)$ as the outcome by using both parents' reported and children's self-reported outcomes (children's quality of life). The SMBQ and $\mathrm{KINDL}^{\mathrm{R}}$ (total score) were chosen for the analysis because they were the main intervention outcome variables for assessing the changes in parents' and their children's well-being. Post hoc power is the retrospective power of an observed effect based on the sample size and parameter estimates derived from a given data set.

\section{Results}

There were no significant differences in children's gender or age between the intervention and control groups. Also, the distribution of children having type I diabetes versus functional disability was similar in both groups.

There were no significant group $\times$ time interaction on children's quality of life. However, the post hoc analysis suggests a significant intervention effect from pre to post measures both in children's self-reported and their parents' reported social relationships (Friends subscale), indicating improvements in children's relationships with peers. Mean scores, standard deviations, interactions, and both betweenand within-group effect sizes are presented in Table 4.

\section{Mediation Analysis: Indirect Effects on Children's Quality of Life}

Standardized parameter estimates of the direct and indirect paths, standard errors, their corresponding significance effects, and confidence intervals for models with significant indirect effects are provided in Tables 5 and 6. Some of the models were corrected based on the modification indices in order to obtain good fits to the models according to applied goodness-of-fit measures (Hu \& Bentler, 1999). These corrections are reported in Tables 5 and 6. Post hoc power analysis indicated a $94 \%$ probability of detecting a significant indirect effect on child-reported outcomes and a $50 \%$ probability regarding parent-reported outcomes with respect to the main outcome variables (SMBQ and $\mathrm{KINDL}^{\mathrm{R}}$ total).

\section{Parents' reports}

The intervention had significant indirect effects on parents' evaluations of their children's quality of life concerning family and other social relationships, as well as on physical well-being. Decrease in parents' burnout symptoms mediated the intervention effects on total quality of life (CI $[0.026,0.301])$ and subscales of family (CI [0.025, 0.312]) and friends (CI [0.010, 0.258]). In addition, an increase in mindfulness skills (CI [0.043, 0.431]), especially in describing (CI $[0.005,0.337])$ and non-reacting (CI [0.031, 0.350]), but also in cognitive defusion (CI [0.003, 0.220]), mediated the effects on the family subscale. Increase in nonreacting mediated the effect on physical well-being (CI $[0.024,0.335])$. Psychological flexibility (AAQ) did not mediate any intervention effects on any outcome variables. All in all, 14\% of the parents' reported child outcomes were attributed to the mediating path.

\section{Children's self-reports}

The intervention had significant indirect effects on children's self-reported quality of life concerning self-esteem, family, emotional well-being, and school. Decrease in parents' burnout symptoms (SMBQ) mediated the intervention effects on children's total quality of life (CI $[0.060,0.362])$ and subscales of self-esteem (CI [0.047, $0.361]$ ), emotional well-being (CI [0.040, 0.363]), and school (CI $[0.033,0.336])$. Increase in mindfulness skills, especially in describing, mediated effects on children's total quality of life (FFMQ total CI [0.074, 0.379]; Describe CI [0.009, 0.368]) and subscales of self-esteem (FFMQ total CI [0.088, 0.401]; Describe CI [0.035, 0.342]) and family (Describe CI [0.000, 0.302]). In addition, the mindfulness skill acting with awareness mediated the intervention effect on children's self-esteem (CI [0.013, 0.262]). Psychological flexibility (AAQ) and cognitive defusion (CFQ) did not mediate any intervention effects on children's self-reported quality of life. All in all, $18 \%$ of the children's self-reported outcomes were attributed to the mediating path. 


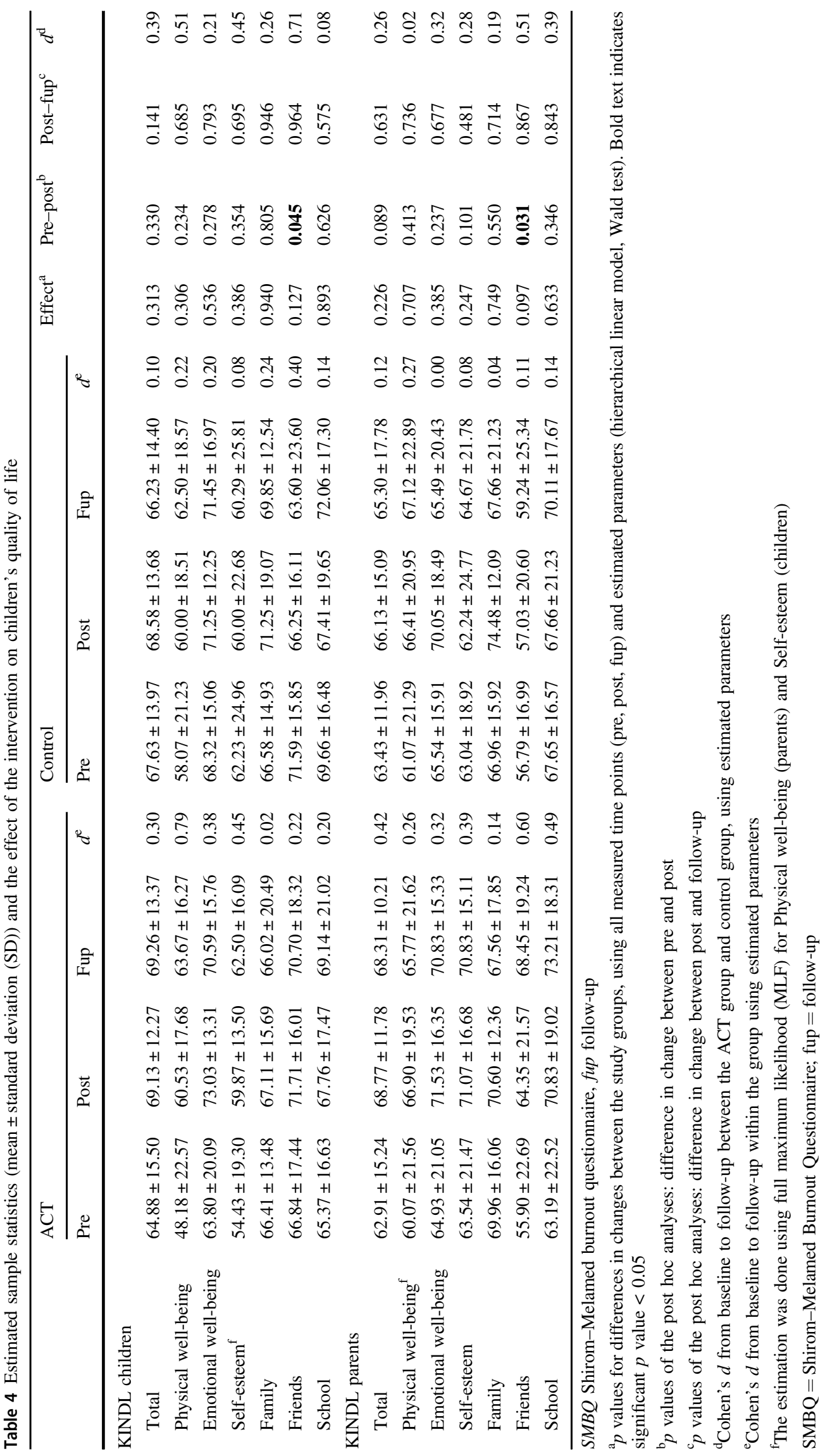


Table 5 Estimates, standard errors, $p$ values and 95\% confidence intervals for significant indirect effects on children's quality of life as reported by their parents

\begin{tabular}{|c|c|c|c|c|c|c|}
\hline Parents' reported outcome Pre-fup & Mediator Pre-fup & & Estimate & SE & $p$-value & Confidence interval \\
\hline \multirow[t]{2}{*}{ KINDL total } & \multirow[t]{2}{*}{$\mathrm{SMBQ}^{\mathrm{a} 1}$} & Indirect $a \times b$ & 0.112 & 0.063 & 0.073 & $0.026,0.301^{b}$ \\
\hline & & Direct $c^{\prime}$ & -0.029 & 0.153 & 0.849 & $-0.309,0.282$ \\
\hline \multirow[t]{10}{*}{ Family } & \multirow[t]{2}{*}{ SMBQ } & Indirect $a \times b$ & 0.133 & 0.069 & 0.055 & $0.025,0.312^{b}$ \\
\hline & & Direct $c^{\prime}$ & -0.237 & 0.159 & 0.136 & $-0.505,0.139$ \\
\hline & \multirow[t]{2}{*}{ CFQ } & Indirect $a \times b$ & 0.079 & 0.053 & 0.138 & $0.003,0.220^{b}$ \\
\hline & & Direct $c^{\prime}$ & -0.183 & 0.125 & 0.144 & $-0.401,0.099$ \\
\hline & \multirow[t]{2}{*}{ FFMQ } & Indirect $a \times b$ & 0.193 & 0.097 & 0.048 & $0.043,0.431^{b}$ \\
\hline & & Direct $c^{\prime}$ & -0.269 & 0.151 & 0.074 & $-0.533,0.071$ \\
\hline & \multirow[t]{2}{*}{ Describe } & Indirect $a \times b$ & 0.108 & 0.081 & 0.185 & $0.005,0.337^{\mathrm{b}}$ \\
\hline & & Direct $c^{\prime}$ & -0.190 & 0.145 & 0.188 & $-0.434,0.155$ \\
\hline & \multirow[t]{2}{*}{ Non-react ${ }^{\mathrm{a}^{2}}$} & Indirect $a \times b$ & 0.157 & 0.077 & 0.043 & $0.031,0.350^{b}$ \\
\hline & & Direct $c^{\prime}$ & -0.252 & 0.152 & 0.097 & $-0.507,0.103$ \\
\hline \multirow[t]{2}{*}{ Friends } & \multirow[t]{2}{*}{$\mathrm{SMBQ}^{\mathrm{a} 3}$} & Indirect $a \times b$ & 0.098 & 0.059 & 0.094 & $0.010,0.258^{b}$ \\
\hline & & Direct $c^{\prime}$ & 0.082 & 0.144 & 0.571 & $-0.237,0.346$ \\
\hline \multirow[t]{2}{*}{ Physical well-being } & \multirow[t]{2}{*}{ Non-react } & Indirect $a \times b$ & 0.137 & 0.077 & 0.073 & $0.024,0.335^{b}$ \\
\hline & & Direct $c^{\prime}$ & -0.121 & 0.136 & 0.373 & $-0.349,0.205$ \\
\hline
\end{tabular}

${ }^{a}$ Models corrected based on the modification indices. Added estimated parameters: (1) SMBQ change score of KINDL total pre score; (2) Family change score of non-react pre score; and (3) correlation of residuals: SMBQ pre score with Friends pre score.

${ }^{\mathrm{b}}$ Significant indirect effects based on the $95 \%$ confidence intervals not including zero.

Table 6 Estimates, standard errors, $p$ values and 95\% confidence intervals for significant indirect effects on children's self-reported quality of life

\begin{tabular}{|c|c|c|c|c|c|c|}
\hline Self-reported outcome Pre-fup & Mediator Pre-fup & & Estimate & SE & $p$ value & Confidence interval \\
\hline \multirow[t]{6}{*}{ KINDL total } & \multirow[t]{2}{*}{ SMBQ } & Indirect $a \times b$ & 0.189 & 0.075 & 0.012 & $0.060,0.362^{b}$ \\
\hline & & Direct $c^{\prime}$ & -0.042 & 0.164 & 0.798 & $-0.365,0.270$ \\
\hline & \multirow[t]{2}{*}{ FFMQ $^{\mathrm{a} 1}$} & Indirect $a \times b$ & 0.226 & 0.080 & 0.005 & $0.074,0.379^{b}$ \\
\hline & & Direct $c^{\prime}$ & -0.007 & 0.147 & 0.961 & $-0.289,0.297$ \\
\hline & \multirow[t]{2}{*}{ Describe $^{\mathrm{a} 2}$} & Indirect $a \times b$ & 0.137 & 0.093 & 0.140 & $0.009,0.368^{b}$ \\
\hline & & Direct $c^{\prime}$ & 0.061 & 0.149 & 0.684 & $-0.209,0.378$ \\
\hline \multirow[t]{8}{*}{ Self-esteem } & \multirow[t]{2}{*}{ SMBQ } & Indirect $a \times b$ & 0.167 & 0.076 & 0.028 & $0.047,0.361^{b}$ \\
\hline & & Direct $c^{\prime}$ & -0.014 & 0.163 & 0.931 & $-0.330,0.285$ \\
\hline & \multirow[t]{2}{*}{$\mathrm{FFMQ}^{\mathrm{a} 3}$} & Indirect $a \times b$ & 0.230 & 0.079 & 0.004 & $0.088,0.401^{b}$ \\
\hline & & Direct $c^{\prime}$ & 0.009 & 0.150 & 0.951 & $-0.300,0.293$ \\
\hline & \multirow[t]{2}{*}{ Describe $^{\mathrm{a} 4}$} & Indirect $a \times b$ & 0.157 & 0.080 & 0.049 & $0.035,0.342^{b}$ \\
\hline & & Direct $c^{\prime}$ & 0.080 & 0.146 & 0.586 & $-0.220,0.350$ \\
\hline & \multirow[t]{2}{*}{ Awareness $^{\mathrm{a} 5}$} & Indirect $a \times b$ & 0.112 & 0.064 & 0.078 & $0.013,0.262^{b}$ \\
\hline & & Direct $c^{\prime}$ & 0.085 & 0.163 & 0.603 & $-0.240,0.408$ \\
\hline \multirow[t]{2}{*}{ Family } & \multirow[t]{2}{*}{ Describe } & Indirect $a \times b$ & 0.097 & 0.077 & 0.210 & $0.00,0.302^{b}$ \\
\hline & & Direct $c^{\prime}$ & -0.132 & 0.182 & 0.467 & $-0.435,0.320$ \\
\hline \multirow[t]{2}{*}{ Emotional well-being } & \multirow[t]{2}{*}{ SMBQ } & Indirect $a \times b$ & 0.160 & 0.078 & 0.041 & $0.040,0.363^{b}$ \\
\hline & & Direct $c^{\prime}$ & -0.111 & 0.191 & 0.561 & $-0.445,0.292$ \\
\hline \multirow[t]{2}{*}{ School } & \multirow[t]{2}{*}{ SMBQ } & Indirect $a \times b$ & 0.163 & 0.076 & 0.031 & $0.033,0^{3} 36^{b}$ \\
\hline & & Direct $c^{\prime}$ & -0.322 & 0.198 & 0.104 & $-0.653,0.111$ \\
\hline
\end{tabular}

${ }^{a}$ Models corrected based on the modification indices. Added estimated parameters: (1) FFMQ change score of KINDL total pre score; (2) Describe change score of KINDL total pre score; (3) Self-esteem pre score of FFMQ change score; (4) Self-esteem pre score of Describe change score; (5) Self-esteem pre score of Awareness change score

${ }^{\mathrm{b}}$ Significant indirect effects based on the $95 \%$ confidence intervals not including zero 


\section{Discussion}

The purpose of the current study was to investigate whether an online ACT intervention for parents has effects on their children's quality of life through improvements in the parents' well-being and psychological flexibility processes. Children's quality of life was assessed both based on their self-reports and their parents' evaluations.

There were no statistically significant direct effects caused by the intervention on children's quality of life. However, the between-group ES at the follow-up time indicated a medium-sized $(d \geq 0.50)$ difference in change for children's self-reported physical well-being and social relationships (friends) as well as in parents' reported social relationships (friends), in both cases in favor of the ACT group. These findings suggest that an online ACT intervention for parents can have clinical importance for children's well-being and social functioning. However, these results should be interpreted cautiously, considering the absence of significant treatment effects. In addition, benefits of the parental ACT intervention for the children seem to be dependent on changes in their parents' well-being, as shown by the mediation analysis.

The mediation analysis indicated indirect effects on children's quality of life through improvements in parental well-being and mindfulness skills. Parents' evaluations and children's self-reports partly indicated changes in different subscales. The intervention had significant indirect effects on parents' evaluations of their children's quality of life concerning family and other social relationships as well as physical well-being. The effect on family relations was mediated by a decrease in parents' burnout symptoms and by improvements in mindfulness skills, describing, nonreacting, and cognitive defusion. In addition, decreases in parents' burnout symptoms mediated the intervention effects on their children's relations with friends, and improvements in the parents' non-reacting to inner experiences mediated the effects on their children's physical wellbeing as evaluated by the parents themselves.

Regarding children's self-reported quality of life, the online ACT intervention had significant indirect effects on the subscales of self-esteem, family, emotional well-being, and school. The effect on children's self-esteem was mediated by a decrease in their parents' burnout symptoms as well as improvements in mindfulness skills, describing, and acting with awareness. Increases in describing also mediated effects on family relations, while decreases in burnout symptoms mediated effects on children's emotional well-being as well as on functioning in school/kindergarten.

Based on the parents' evaluations of their children's quality of life, indirect effects of the online ACT intervention were seen mostly in children's social relationships, especially the relationship with their parents. Based on the children's self-reports, an indirect effect was seen also in the subscales relating to children's inner experiences (self-esteem and emotional well-being). It is plausible that the parents were more sensitive in noticing differences in their children's communication and relation with them and other people (e.g., "My child got on well with us as parents"; "My child did things together with friends"), as well as in physical wellbeing ("My child was tired and worn out"); whereas the children themselves could perhaps better reflect their inner experiences (e.g., "I was proud of myself"; "I felt alone").

Our results suggest that an ACT intervention affecting parents' psychological flexibility related processes-such as defusion, describing, non-reacting to one's inner experiences, and acting with awareness - can be beneficial for improving the quality of life of children having chronic conditions. Parents are likely more capable of communicating with their child in an adaptive manner when better able to handle their own inner experiences in more accepting and non-reactive ways. Our results are in line with previous research indicating a positive association between parents' psychological flexibility and positive parenting styles (Burke et al., 2014; Cheron et al., 2009; Shea \& Coyne, 2011), as well as with children's psychological outcomes (Cheron et al., 2009; Williams et al., 2012). In addition, adopting a mindful parenting style has been associated with several indicators of positive psychological functioning and increased well-being in children (Bögels et al., 2014; Moreira et al., 2018; Parent et al., 2016). Also in line with our results, several ACT-integrated parenting interventions have shown improvements in child physical and psychological functioning, decreases in parents' level of stress, depression and anxiety, and improvements in a number of ACT mechanisms of change outcomes, including mindfulness, acceptance, and cognitive defusion (Byrne et al., 2021). Together, these findings support the utilization of acceptance and mindfulness methods by parents in order to support the well-being of their children.

\section{Limitations}

The findings of the present study should be considered in the context of certain limitations. Firstly, the changes in both mediators and outcomes were measured from pre to follow-up. Thus, the present test of mediation did not meet all of the criteria that are desirable in mediation analysis (Stice et al., 2007). The time period from the pre to follow-up was chosen for the final analysis in order to capture the largest changes in variables. It is possible that the changes in the children's outcomes took place before or at the same time as the changes in their parents' well-being and psychological processes. In future, more frequent measures of different processes are needed in order to 
investigate the interrelationship between changes in parents' and children's outcomes.

Secondly, another limitation was the use of self-reports, which can influence the validity of a study. The baseline survey questions may have "primed" parents regarding the aims of the online intervention and thereby impacted their answers at the post-intervention and follow-up measurement points. In addition, the children's quality of life was assessed using their self-reports and their parents' reports. While these provide different perspectives on the children's quality of life, it is possible that the children's reports had an influence on their parents' reports in the online survey. Instead of reporting behavior retrospectively over a long period of time, examining parents' activities and their children's behavior in daily life, such as by using experience sampling methods, might provide more detailed information about the dynamics between parents and their children and the factors affecting their well-being.

Thirdly, the sample size for statistical analysis was small, which increases the likelihood of a type II error (false negative). Thus, the findings should be interpreted with caution. More similar studies are needed in order to validate the findings. In addition, the majority of the participants were mothers $(81 \%)$, and accordingly the results cannot be generalized to fathers. All in all, our results should be interpreted in the context of parents (mostly mothers) suffering from burnout symptoms, have children with chronic conditions, and participated in an online ACT treatment.

\section{Conclusions and Future Directions}

The online ACT intervention for parents of children with chronic conditions had indirect effects on the children's quality of life, mediated by changes in parental well-being and psychological flexibility related processes such as defusion, acting with awareness, describing, and non-reacting to one's inner experiences. These results suggest that parents' psychological flexibility needs to be improved in order to enable a better quality of life for their children suffering from chronic conditions. Online interventions are a way to provide this type of treatment to parents remotely. In future, more research is needed to understand what behavioral changes in parents can yield positive outcomes for their children. Ecological momentary assessment (EMA) of parental activities in daily life could be one way to examine this in more detail.

Funding This study was funded by the grant from the County Council of Värmland, Sweden. Open access funding provided by Karlstad University.

\section{Compliance with Ethical Standards}

Conflict of Interest The authors declare no competing interests.
Ethical Approval The study had an ethical approval by the Regional Ethical Review Board of Uppsala University in Uppsala, Sweden. All participants gave their written informed consent for their participation in the study.

Publisher's note Springer Nature remains neutral with regard to jurisdictional claims in published maps and institutional affiliations.

Open Access This article is licensed under a Creative Commons Attribution 4.0 International License, which permits use, sharing, adaptation, distribution and reproduction in any medium or format, as long as you give appropriate credit to the original author(s) and the source, provide a link to the Creative Commons license, and indicate if changes were made. The images or other third party material in this article are included in the article's Creative Commons license, unless indicated otherwise in a credit line to the material. If material is not included in the article's Creative Commons license and your intended use is not permitted by statutory regulation or exceeds the permitted use, you will need to obtain permission directly from the copyright holder. To view a copy of this license, visit http://creativecommons. org/licenses/by/4.0/.

\section{References}

Alfonsson, S., Wallin, E., \& Maathz, P. (2017). Factor structure and validity of the Depression, Anxiety and Stress Scale-21 in Swedish translation. Journal of Psychiatric and Mental Health Nursing, 24(2-3), 154-162

Appels, A., \& Schouten, E. (1991). Burnout as a risk factor for coronary heart disease. Behavioral Medicine, 17(2), 53-59

Arifin, W. N. (2012). Random sampling and allocation using SPSS. Education in Medicine Journal, 4(1). https://doi.org/10.5959/ eimj.v4i1.4

Baer, R. A., Smith, G. T., Lykins, E., Button, D., Krietemeyer, J., Sauer, S., \& Williams, J. M. (2008). Construct validity of the Five Facet Mindfulness Questionnaire in meditating and nonmeditating samples. Assessment, 15(3), 329-342. https://doi.org/10. 1177/1073191107313003

Bennett, D. S. (1994). Depression among children with chronic medical problems: A meta-analysis. Journal of Pediatric Psychology, 19(2), 149-169

Blackledge, J. T., \& Hayes, S. C. (2006). Using acceptance and commitment training in the support of parents of children diagnosed with autism. Child \& Family Behavior Therapy, 28(1), $1-18$

Bögels, S. M., Hellemans, J., van Deursen, S., Römer, M., \& van der Meulen, R. (2014). Mindful parenting in mental health care: Efects on parental and child psychopathology, parental stress, parenting, coparenting, and marital functioning. Mindfulness, 5 (5), 536-551

Bond, F. W., Hayes, S. C., Baer, R. A., Carpenter, K. M., Guenole, N., Orcutt, H. K., \& Zettle, R. D. (2011). Preliminary psychometric properties of the acceptance and action questionnaire-II: a revised measure of psychological inflexibility and experiential avoidance. Behavior Therapy, 42(4), 676-688

Buhrman, M., Skoglund, A., Husell, J., Bergström, K., Gordh, T., Hursti, T., \& Andersson, G. (2013). Guided internet-delivered acceptance and commitment therapy for chronic pain patients: A randomized controlled trial. Behaviour Research and Therapy, 51 (6), 307-315

Burke, K., Muscara, F., McCarthy, M., Dimovski, A., Hearps, S., Anderson, V., \& Walser, R. (2014). Adapting acceptance and 
commitment therapy for parents of children with life-threatening illness: Pilot study. Families, Systems, \& Health, 32(1), 122

Byrne, G., Ghráda, Á. N., O’Mahony, T., \& Brennan, E. (2021). A systematic review of the use of acceptance and commitment therapy in supporting parents. Psychology and Psychotherapy: Theory, Research and Practice, 94, 378-407

Cheron, D. M., Ehrenreich, J. T., \& Pincus, D. B. (2009). Assessment of parental experiential avoidance in a clinical sample of children with anxiety disorders. Child Psychiatry and Human Development, 40(3), 383-403

Chong, Y. Y., Mak, Y. W., Leung, S. P., Lam, S. Y., \& Loke, A. Y. (2019). Acceptance and commitment therapy for parental management of childhood asthma: An RCT. Pediatrics, 143(2). https://doi.org/10.1542/peds.2018-1723

de Bruin, E. I., Zijlstra, B. J., Geurtzen, N., van Zundert, R. M., van de Weijer-Bergsma, E., Hartman, E. E., \& Bögels, S. M. (2014). Mindful parenting assessed further: Psychometric properties of the Dutch version of the Interpersonal Mindfulness in Parenting Scale (IM-P). Mindfulness, 5(2), 200-212

Evans, T., Whittingham, K., \& Boyd, R. (2012). What helps the mother of a preterm infant become securely attached, responsive and well-adjusted? Infant Behavior and Development, 35(1), $1-11$

Gillanders, D. T., Bolderston, H., Bond, F. W., Dempster, M., Flaxman, P. E., Campbell, L., \& Ferenbach, C. (2014). The development and initial validation of the Cognitive Fusion Questionnaire. Behavior Therapy, 45(1), 83-101

Gouveia, M., Carona, C., Canavarro, M., \& Moreira, H. (2016). Selfcompassion and dispositional mindfulness are associated with parenting styles and parenting stress: The mediating role of mindful parenting. Mindfulness, 7(3), 700-712

Hahs, A. D., Dixon, M. R., \& Paliliunas, D. (2019). Randomized controlled trial of a brief acceptance and commitment training for parents of individuals diagnosed with autism spectrum disorders. Journal of Contextual Behavioral Science, 12, 154-159

Hayes, S. C., Luoma, J. B., Bond, F. W., Masuda, A., \& Lillis, J. (2006). Acceptance and commitment therapy: Model, processes and outcomes. Behaviour Research and Therapy, 44(1), 1-25

Henry, J. D., \& Crawford, J. R. (2005). The short-form version of the Depression Anxiety Stress Scales (DASS-21): Construct validity and normative data in a large non-clinical sample. British Journal of Clinical Psychology, 44(2), 227-239

Hu, L. T., \& Bentler, P. M. (1999). Cutoff criteria for fit indexes in covariance structure analysis: Conventional criteria versus new alternatives. Structural Equation Modeling: A Multidisciplinary Journal, 6(1), 1-55

Kanstrup, M., Wicksell, R. K., Kemani, M., Wiwe Lipsker, C., Lekander, M., \& Holmström, L. (2016). A clinical pilot study of individual and group treatment for adolescents with chronic pain and their parents: Effects of acceptance and commitment therapy on functioning. Children, 3(4), 30

Kashdan, T. B., \& Rottenberg, J. (2010). Psychological flexibility as a fundamental aspect of health. Clinical Psychology Review, 30(7), $865-878$

Kemani, M. K., Kanstrup, M., Jordan, A., Caes, L., \& GauntlettGilbert, J. (2018). Evaluation of an intensive interdisciplinary pain treatment based on acceptance and commitment therapy for adolescents with chronic pain and their parents: A nonrandomized clinical trial. Journal of Pediatric Psychology, 43(9), 981-994

Kim-Cohen, J., Moffitt, T. E., Taylor, A., Pawlby, S. J., \& Caspi, A. (2005). Maternal depression and children's antisocial behavior: Nature and nurture effects. Archives of General Psychiatry, 62(2), 173-181

Lappalainen, P., Granlund, A., Siltanen, S., Ahonen, S., Vitikainen, M., Tolvanen, A., \& Lappalainen, R. (2014). ACT internet-based vs face-to-face? A randomized controlled trial of two ways to deliver Acceptance and commitment therapy for depressive symptoms: An 18-month follow-up. Behaviour Research and Therapy, 61, 43-54

Lilja, J. L., Frodi-Lundgren, A., Hanse, J. J., Josefsson, T., Lundh, L.G., Sköld, C., \& Broberg, A. G. (2011). Five facets mindfulness questionnaire-reliability and factor structure: A Swedish version. Cognitive Behaviour Therapy, 40(4), 291-303

Lippold, M. A., Duncan, L. G., Coatsworth, J. D., Nix, R. L., \& Greenberg, M. T. (2015). Understanding how mindful parenting may be linked to mother-adolescent communication. Journal of Youth and Adolescence, 44(9), 1663-1673

Lundgren, T., \& Parling, T. (2017). Swedish acceptance and action questionnaire (SAAQ): A psychometric evaluation. Cognitive Behaviour Therapy, 46(4), 315-326

Lundgren-Nilsson, Å., Jonsdottir, I. H., Pallant, J., \& Ahlborg, G. (2012). Internal construct validity of the Shirom-Melamed burnout questionnaire (SMBQ). BMC Public Health, 12(1), 1

Melamed, S., Kushnir, T., \& Shirom, A. (1992). Burnout and risk factors for cardiovascular diseases. Behavioral Medicine, 18(2), 53-60

Melamed, S., Ugarten, U., Shirom, A., Kahana, L., Lerman, Y., \& Froom, P. (1999). Chronic burnout, somatic arousal and elevated salivary cortisol levels. Journal of Psychosomatic Research, 46 (6), 591-598

Moreira, H., Gouveia, M. J. \& Canavarro, M. C. (2018). Is mindful parenting associated with adolescents' well-being in early and middle/late adolescence? The mediating role of adolescents' attachment representations, self-compassion and mindfulness. Journal of Youth and Adolescence, 47(8), 1771-1788

Muthén, B. O. (1998). Mplus technical appendices (Appendix 5). Muthén \& Muthén

Muthén, L. K., \& Muthén, B. O. (2002). How to use a Monte Carlo study to decide on sample size and determine power. Structural Equation Modeling, 9(4), 599-620

Parent, J., McKee, L. G., Rough, J. N., \& Forehand, R. (2016). The association of parent mindfulness with parenting and youth psychopathology across three developmental stages. Journal of Abnormal Child Psychology, 44(1), 191-202

Preacher, K. J., \& Hayes, A. F. (2008). Asymptotic and resampling strategies for assessing and comparing indirect effects in multiple mediator models. Behavior Research Methods, 40(3), 879-891

Preacher, K. J., Zyphur, M. J., \& Zhang, Z. (2010). A general multilevel SEM framework for assessing multilevel mediation. Psychological Methods, 15(3), 209

Ravens-Sieberer, U., \& Bullinger, M. (1998). Assessing health-related quality of life in chronically ill children with the German KINDL: First psychometric and content analytical results. Quality of Life Research, 7(5), 399-407

Ravens-Sieberer, U., Heilmann, M., \& Walleser, S. (2000). Assessment of quality of life in young children with a computer-assisted touch screen program (CAT-Screen) - reliability, validity and feasibility. Quality of Life Research, 9, 298-298

Ruiz, F. J. (2010). A review of acceptance and commitment therapy (ACT) empirical evidence: Correlational, experimental psychopathology, component and outcome studies. International Journal of Psychology and Psychological Therapy, 10(1), 125-162

Schoemann, A. M., Boulton, A. J., \& Short, S. D. (2017). Determining power and sample size for simple and complex mediation models. Social Psychological and Personality Science, 8(4), 379-386

Shea, S. E., \& Coyne, L. W. (2011). Maternal dysphoric mood, stress, and parenting practices in mothers of Head Start preschoolers: The role of experiential avoidance. Child \& Family Behavior Therapy, 33(3), 231-247

Shirom, A., \& Melamed, S. (2006). A comparison of the construct validity of two burnout measures in two groups of professionals. International Journal of Stress Management, 13(2), 176 
Stice, E., Presnell, K., Gau, J., \& Shaw, H. (2007). Testing mediators of intervention effects in randomized controlled trials: An evaluation of two eating disorder prevention programs. Journal of Consulting and Clinical Psychology, 75(1), 20

Thoemmes, F., MacKinnon, D. P., \& Reiser, M. R. (2010). Power analysis for complex mediational designs using Monte Carlo methods. Structural Equation Modeling, 17(3), 510-534

Toker, S., Shirom, A., Shapira, I., Berliner, S., \& Melamed, S. (2005). The association between burnout, depression, anxiety, and inflammation biomarkers: C-reactive protein and fibrinogen in men and women. Journal of Occupational Health Psychology, 10 (4), 344

Wallace, D. P., Woodford, B., \& Connelly, M. (2016). Promoting psychological flexibility in parents of adolescents with chronic pain: Pilot study of an 8-week group intervention. Clinical Practice in Pediatric Psychology, 4(4), 405
Whittingham, K., Sanders, M. R., McKinlay, L., \& Boyd, R. N. (2016). Parenting intervention combined with acceptance and commitment therapy: A trial with families of children with cerebral palsy. Journal of Pediatric Psychology, 41(5), 531-542. https://doi.org/10.1093/jpepsy/jsv118

Williams, K. E., Ciarrochi, J., \& Heaven, P. C. (2012). Inflexible parents, inflexible kids: A 6-year longitudinal study of parenting style and the development of psychological flexibility in adolescents. Journal of Youth and Adolescence, 41(8), 1053-1066

Witt, W. P., \& DeLeire, T. (2009). A family perspective on population health: The case of child health and the family. WMJ: official publication of the State Medical Society of Wisconsin, 108(5), 240

Zhao, X., Lynch, J. G., \& Chen, Q. (2010). Reconsidering Baron and Kenny: Myths and truths about mediation analysis. Journal of Consumer Research, 37(2), 197-206 